\title{
ASPECTOS JURÍDICOS DO REGALISMO NO BRASIL IMPERIAL
}

\author{
Camila R. de M. S. Arruda ${ }^{1}$ \\ Leticia Maria de O. Borges ${ }^{2}$
}

RESUMO: A presente pesquisa traz a análise dos aspectos jurídicos do Regalismo no Brasil especificamente no período imperial. O Regalismo foi uma herança trazida pela corte portuguesa, onde o Estado interferia diretamente dentro da Igreja católica, religião oficial do Império, podendo inclusive nomear os clérigos, os párocos e os bispos. O período imperial foi marcado por muitos conflitos entre a Igreja e seus membros, porém neste mesmo período, os membros da Igreja participavam ativamente da administração pública através de exercício de cargos públicos e a Igreja era mantida em sua grande parte com o erário público.

Palavras-chaves: Igreja católica; Regalismo; Religião oficial; Intervenção do Estado; Constituição de 1824.

\section{LEGAL ASPECTS OF REGALISM IN IMPERIAL BRAZIL}

ABSTRACT: The present research brings the analysis of the juridical aspects of Regalism in Brazil specifically in the imperial period. Regalism was an inheritance brought by the Portuguese court, where the state interfered directly within the Catholic Church, the official religion of the Empire, and could even appoint clerics, parish priests and bishops. The imperial period was marked by many conflicts between the Church and its members, but in this same period the members of the Church actively participated in the public administration through public office and the Church was largely held by the public purse.

Keywords: Catholic Church; Regalism; Official religion; Station intervention; Constitution of 1824

1. Introdução

A Igreja católica é uma instituição que influenciou a sociedade e a política interna desde a colonização do Brasil. A religiosidade foi trazida ao Brasil pelos primeiros desbravadores e

\footnotetext{
${ }^{1}$ Doutoranda em Direito PPGD-UVA. Mestra em Ciências Ambientais pela UVA. Professora da Universidade Veiga de Almeida dos Cursos de Direito e Administração. Endereço: Rua Ibituruna 54 casa 13, Tijuca, Rio de Janeiro, RJ, Brasil. CEP: 20271-020. E-mail: profcamilaarruda@gmail.com

${ }^{2}$ Doutora em Direito pelo PPGD-UVA, Mestra em Direito pela UGF, Professora da Universidade Veiga de Almeida e da Universidade Estácio de Sá dos cursos de Direito e Relações Internacionais. Endereço: Rua Batista da Costa 257, Mosela, Petrópolis, RJ, Brasil. E-mail: ticha_borges@yahoo.com.br
} 
contribuiu fortemente para a formação cultural do Brasil. A formação do Estado teve a influência direta da Igreja católica e seus costumes, eram os costumes praticados na época.

O regalismo já era praticado em Portugal na época em que Dom João VI se encaminhou ao Brasil com a família real e a Corte Portuguesa. Com a chegada da família real ao Brasil pudemos observar um crescimento muito grande da colônia, passando o Rio de Janeiro por mudanças de todas as ordens, não ficando a igreja católica longe delas.

O fim da época colonial com a Proclamação da Independência em 7 de setembro de 1822, iniciou uma fase legislativa mais liberal, onde foi admitido no artigo 179 da Constituição de 1824 que a religião católica era a religião oficial no Brasil. (Brasil, 1824, pág.65)

“Art. 5. A Religião Catholica Apostolica Romana continuará a ser a Religião do Imperio. Todas as outras Religiões serão permittidas com seu culto domestico, ou particular em casas para isso destinadas, sem fórma alguma exterior de Templo”.

Assim no artigo 179 ficou estabelecida restou clara a possibilidade de liberdade de culto, desde que em lugares fechados, conforme descrito a seguir (Brasil, 1824, pág. 85)

“Art. 179. A inviolabilidade dos Direitos Civis, e Politicos dos Cidadãos Brazileiros,que tem por base a liberdade, a segurança individual, e a propriedade, é garantida pela Constituição do Imperio, pela maneira seguinte.

V. Ninguem póde ser perseguido por motivo de Religião, uma vez que respeite a do Estado, e não offenda a moral Publica”.

O período imperial trouxe entre 1824 e 1889 um período de antítese, mesmo sendo o catolicismo a religião, esse período foi marcado por uma série de conflitos e atentados contra a Igreja e seus membros.

O regalismo se apoderou diretamente das normas do governo imperial, passando a fazer parte da administração pública, atuando diretamente nas questões civis e inclusive sendo mantidas em sua grande parte pelo erário público. Nessa época, não se sabia aonde começava o Estado e terminava a Igreja.

A presente pesquisa busca discutir de que forma o Estado interferiu diretamente na Igreja católica no período imperial? Para responder a esse questionamento fez-se necessário analisar a importância da Constituição de 1824 para o fortalecimento do Estado em relação a Religião católica, através da identificação dos aspectos legais que interferiram diretamente na 
relação Estado e Igreja; avaliar as interferências do Estado na Igreja e as suas consequências e analisar de que forma a Igreja católica recebia essa interferência do Estado nos seus atos, inclusive interferindo na nomeação de seus padres e bispos.

A metodologia utilizada é a revisão bibliográfica em livros, artigos científicos e nas Constituições de 1824, na I Constituição do Arcebispado da Bahia e no Código Criminal de 1830.

2. O Regalismo: herança do reino português

O Brasil herdou muitas influências de Portugal, uma delas foi o regalismo, que permaneceu vigente no país até o Decreto datado de 7 de janeiro de 1890, onde houve a separação do Estado.

A melhor definição sobre o regalismo é do privilégio que a Santa Sé concedia aos reis soberanos num ponto relativo a à disciplina da Igreja. Esse privilégio acontecia quando a religião oficial do Estado passa a ser a católica.

A doutrina regalista foi codificada por Palatino, teólogo de Pádua, que escreveu o “Defensorium paces”. Palatino pregava a congregação dos fiéis através de uma doutrina única, transformada em direito comum a toda a sociedade. Através do regalismo, o poder da Igreja poderia ser transferido aos príncipes, no caso deste ser um fiel da Igreja ou aos bispos, em caso de comprovada infidelidade dos bispos a Igreja Católica.

Papa João XXII, na metade do século X, condenou essa restrição aos privilégios dos pontífices. A partir deste momento histórico, a doutrina regalista passou a ser objeto de controvérsias e disputas entre a Igreja e o Estado. A Igreja sempre preocupada em manter sua unidade, discutiu durante os concílios, a forma de manter os poderes do Pontífice sem chocarse diretamente com os soberanos.

O Rei Luís XIV, o grande, que disse: “O Estado sou eu”, criou o galicalismo, onde os pontífices não teriam nenhum poder sobre os reis, ou seja, não exerceriam nenhuma ingerência sobre seus atos ou decisões, nem de forma indireta. A autoridade da Sé Apostólica é regulada pelas leis canônicas, junto com as leis e os costumes que vigoravam no Reino e a Igreja.

O galicalismo, em Portugal, trouxe uma certa independência em relação aos pontífices. O auge do conflito entre o rei e o Papa ocorreu em meados do século XVII, nesta ocasião o Papa recusou a reconhecer D. João IV como soberano de Portugal por conta da relação que o Pontífice tinha com o Rei da Espanha. 
Marques de Pombal, Ministro português do reinado de D. José I (1750 a 1770), fez com que o regalismo tomasse mais força em Portugal. Neste período tornou-se oficial que as regalias do rei seriam maiores que as do papa, tirando dos bispos o poder de sagrar sacerdotes sem a autorização do governo.

Dom João VI, ao chegar no Brasil em 1808, não abdicou das regalias reais, sendo estas, utilizadas nos governos imperiais que o sucederam. As longas viagens de navio, ida e volta, do Rio para Roma, e também a necessidade de Dom João tinha de criar uma capela real, fizeram com que Dom João VI, através de Decreto, passasse por cima da solicitação feita pelo núncio apostólico ao Pontífice, criando a capela real.

A criação da capela real foi reconhecida quatro meses depois, por ato de Dom Lourenço Caleppi, com a autorização do Papa, onde restou clara a importância da instalação de uma capela real onde a família real estivesse residindo.

Em 1810, a Irmandade da Santa Cruz dos militares solicitou a Dom João VI a interferência junto ao episcopado, para que fosse feita a nomeação de um capelão para que fosse pago com seus recursos o seu pároco.

Diante da adoção do regalismo no caso em tela, Scampini manifestou-se (1978, pág. 30):

\footnotetext{
“O padroado (regalismo) não exime as igrejas por si só, da jurisdição dos bispos, como vem sendo de prática no Brasil e em Portugal. Se os bispos não nomeassem os párocos, então que o fizessem os soberanos, e aqui, no caso, mais ainda, o Príncipe Regente, porque ela mesma, pelo fato de ser de militares, devia considerar, sob a imediata proteção dele, como a Santa Casa de Misericórdia”.
}

Dom João VI era muito cuidadoso em relação as suas prerrogativas e direitos em relação aos núncios e ao Papa, se preocupava em manter o seu papel de soberano; ele protagonizou vários episódios de conflito com a Igreja, onde inclusive suas nomeações de bispos não foram reconhecidas pela Santa Sé. Esses episódios acabaram por formar uma guerra de braços entre a Igreja e o Regente.

O regalismo manteve-se ativo durante todo o período imperial, onde o Estado permaneceu exercendo um papel intervencionista em relação da Igreja, pautando-se em manter a soberania do Estado, pautando-se em proteger a religião oficial e os costumes da sociedade a época. No capítulo a seguir veremos os aspectos gerais da Igreja no período Imperial, onde poderemos verificar o papel da Igreja e a sua influência social. 


\section{Aspectos gerais da Igreja Católica no Brasil Império}

A Igreja católica no período de colonização, fortaleceu-se como religião oficial no Brasil. Durante o período colônia, o catolicismo era a religião praticada no Brasil, onde trouxe, através do trabalho de seus padres, bispos e religiosos além do ensino religioso, contribuição para a formalização do ensino confessional.

Após a proclamação da independência em 7 de setembro de 1822, a Igreja passou a desempenhar um papel diferente, neste período a Igreja perdeu força e já não interferia mais diretamente nas decisões, inclusive, tendo o imperador um papel de cercear os atos da Igreja, passando ele a ter o papel determinante nas decisões que incluíam inclusive a Igreja.

Em 21 de janeiro de 1823, o Ministro da Justiça, Miranda Montenegro, enviou instruções ao Bispo D. Mateus, orientando que chamasse atenção dos clérigos a respeito de comportamentos devassos, impuros e escandalosos. (Brasil, 1978, pág. 53). Pouco depois o Fisco liberou a Igreja de pagar a taxa de alvará para a abertura de novas paróquias.

Ainda no ano de 1823, o Ministro da Justiça, apreensivo em relação a uma possível tentativa de reconquista de Portugal, interferiu mais uma vez na Igreja, emitindo um aviso aos bispos provinciais sobre a não admissão de outros clérigos até segunda ordem, conforme descrito no texto a seguir. (Brasil, 1978, pág 53)

\footnotetext{
“Outra medida desse tipo ainda tomaria o Ministro da Justiça nesse mesmo ano, o segundo da independência, sendo a mais importante de todos o aviso aos bispos das províncias para que não admitissem novos clérigos em suas jurisdições, até a segunda ordem, diante dos perigos representados por uma possível tentativa de reconquista do Brasil por Portugal (pressionado que estava sendo D. João VI pelos comerciantes de Lisboa nesse sentido). E vindo logo portaria que proibia o Convento de Santo Antonio a admissão de novos noviços- uma proibição essa que se generalizaria em 1855, por aviso do Ministro da Justiça, Senador Nabuco de Araújo.”
}

Cada vez mais sofrendo com as intervenções arbitrárias do Estado e entendendo estar perdendo o poder antes exercido, foi proclamada A Constituição Primeira do Arcebispado da Bahia (1853), documento este, norteador de todos as mudanças e de todo comportamento da Igreja junto a sociedade brasileira a época.

A Constituição do Arcebispado foi adotada por todos os bispos brasileiros, tendo adequação quanto aos costumes locais de cada diocese, através dela não se deixou de ignorar a 
necessidade de fortalecer a imunidade da Igreja, o privilégio do foro e demais regalias existentes a época.

Destacamos a seguir um trecho do Prólogo da Constituição do Arcebispado que traz a visão sobre a Igreja e suas adaptações em relação as mudanças no próprio Estado (Arcebispado da Bahia, 1853, pág. 7)

\begin{abstract}
"E inqueslionayel, que as Leis disciplinares da Igreja se mudão, e se accommodão ás circunstancias do tempo, e que a Igreja, embora seja um Imperio distincto, e separado pelo que pertence ao espiritual dos fieis, com tudo está subordinada ao Imperio Civil. A Fórma de Governo, as Leis patrias, os diversos Codigos, adoptados por uma Nação Catbolica, tem collocado a Igreja na indeclinavel necessidade de modificar sua antiga disciplina. Eis o que encontramos nas presentes Constituições".
\end{abstract}

Embora a Constituição do Arcebispado estabelecesse a normativa para o funcionamento da Igreja, convém enfatizar que em seu prólogo, a Igreja enfatiza o cumprimento da constituição e das leis brasileiras por todos os católicos, devendo os vigários exercer um papel extremamente importante junto aos seus paroquianos, reafirmando a importância do cumprimento das leis do Estado por todos os cidadãos.

Nesta época a Igreja detinha o monopólio sobre os registros, os documentos eram a certidão de batismo, de casamento e de óbito, todos emitidos pela igreja local, exercendo assim uma representação do papel do Estado.

Na visão de Scampini (1978, p. 15) na história nacional seria insolúvel qualquer tentativa de separar a Igreja e o Estado. D. Vital apud Scampini (1978) dizia que não havia questão mais melindrosa e intrínseca do que a relação entre a Igreja e o Estado, sem que ao mesmo tempo se ressintam todas as fibras do corpo social.

Borges e Arruda (2017, pág. 373) trazem a visão que:

\footnotetext{
“A fim de manter o poder, bem como manter o controle social, Portugal usou a força da Igreja, auxiliado por pessoas influentes da colônia que desejavam não apenas a preservação dos valores religiosos, mas sim lucros e benefícios e seus negócios”.
}

No período colonial a inquisição foi a primeira forma de controle social, considerando toda a prática religiosa diversa dos preceitos católicos uma obra do maligno, feitiçaria ou maldição. O julgamento desses “hereges” era feito de forma sumária frente ao Tribunal de Inquisição, que aplicava as penas sem a oitiva de defesa dos acusados. 
A vinda da família real em 1808, trouxe a tentativa de flexibilizar e implantar no Brasil a prática da tolerância religiosa. Um exemplo disso foi o tratado da Aliança e da Amizade, firmado com a Inglaterra, que trouxe a possibilidade de prática religiosa diversa dentro do território brasileiro, impedindo que os ingleses fossem perturbados por professarem uma fé diferente da religião oficial.

\section{A Constituição de 1824 e a religião católica}

A Constituição do Império foi outorgada em 25 de março de 1824 por D. Pedro I. O preâmbulo desta constituição encerra com a invocação da Santíssima Trindade e a expressão “por graça de Deus”. (Scampini, 1978)

Este documento recebeu o nome de Constituição Política do Império do Brazil da Santíssima Trindade, ou seja, carregava no próprio nome o simbolismo da Igreja Católica (Pai, filho e Espírito Santo).

Em seu artigo $5^{\circ}$, a Constituição de 1824, trouxe a seguinte redação:

“A Religião Catholica Apostolica Romana continuará a ser a Religião do Imperio. Todas as outras Religiões serão permittidas com seu culto domestico, ou particular em casas para isso destinadas, sem fórma alguma exterior de Templo”.

O artigo $5^{\circ}$ retrata a importância que a religião católica exercia dentro da sociedade brasileira à época, sendo efetivamente protegida e acima de tudo, tinha prevalência acima de todas as outras religiões.

O imperador também jurava perante o conselho de Estado, manter a religião católica como oficial. Também se fazia necessário professar a religião católica para que recebesse um cargo político.

Art. 103. O Imperador antes de ser acclamado prestará nas mãos do Presidente do Senado, reunidas as duas Camaras, o seguinte Juramento - Juro manter a Religião Catholica Apostolica Romana, a integridade, e indivisibilidade do Imperio; observar, e fazer observar a Constituição Politica da Nação Brazileira, e mais leis do Imperio, e prover ao bem geral do Brazil, quanto em mim couber.(Constituição de 1824) 
O exercício do culto doméstico, fugia ao controle do Imperador, mas o culto externo era reprimido e não poderia ofender a moral pública. O artigo 179 inciso V da Constituição do Império, onde são garantidos os direitos civis do brasileiro, que ninguém pode ser perseguido por motivo religioso, desde que ele estivesse respeitando a religião do Estado e não ofendendo a moral pública.

O papel do Estado junto a Igreja buscava proteger a religião, os costumes, a moral, além de defendê-la dos aventureiros que pudessem aparecer, professando e difundindo novas religiões e credos. A fim de evitar essa interferência externa, competia ao Poder Executivo a nomeação dos bispos e conceder benefícios eclesiásticos, demonstrando uma interferência do estado nas decisões internas de Igreja, como se a Igreja fosse apenas o braço do Estado.

O padroado, assim como a concordata da Santa Sé, eram competências do Poder Executivo conferidos pelo texto constitucional. A partir da Constituição Imperial todas as concordatas da Santa Sé (tratados internacionais firmados pelo Estado da Santa Sé com outros Estados).

\footnotetext{
“Art. 102. O Imperador é o Chefe do Poder Executivo, e o exercita pelos seus ministros de Estado.

São suas principaes attribuições.

II. Nomear Bispos, e prover os Benefcios Ecclesiasticos.

XIV. Conceder, ou negar o Beneplacito aos Decretos dos Concilios, e letras Apostolicas, e quaesquer outras Constituições Ecclesiasticas, que se não oppozerem á Constituição; e precedendo approvação da Assembléa, se contiverem disposição gera”l. (Constituição de 1824, pág.76)
}

Na visão de Scampini (1978, pág. 23) entende-se o direito de padroado, segundo o direito canônico, seria o conjunto de privilégios com certas incumbências que por concessão da Igreja, correspondem aos fundadores católicos da Igreja ou até aos seus sucessores.

Originalmente, na visão do direito eclesiástico, a nomeação dos bispos caberia somente a Santa Sé, que receberia uma lista tríplice para a escolha do sumo pontífice.

Na constituição imperial, o imperador passou a ter o poder, que anteriormente era exercido pelo Papa, de nomear os bispos. Embora o padroado não ter sido instituído pelo regalismo, ele acaba demonstrando os abusos que surgiram nesse período. 
5. A influência do Regalismo na Igreja e os impactos sociais a época

Após a proclamação da independência, com Dom Pedro I oficialmente proclamado imperador do Brasil, ele passou constitucionalmente a ocupar o cargo de chefe de Estado, para resolver as questões em relação a sociedade e sua ordem, e da Igreja no que se relacionava as leis do país.

Afim de possibilitar a melhor relação com Roma, Dom Pedro I nomeou o Monsenhor Francisco Correa Vidigal para governador diocesano (até 1838) enquanto ocorreu o conflito que durou cinco anos, abrangendo a Regência e o Papa Gregório XVI. Papa Gregório recusou a nomeação do bispo eleito, o padre e professor de Direito, Antonio Maria de Moura.

Na visão de Gérson Brasil (1978, pág. 49), o Monsenhor Vidigal, representava diretamente os interesses da coroa, conforme descrito a seguir:

\begin{abstract}
“As instruções levadas por Monsenhor Vidigal, e redigidas por José Bonifácio, como Ministro de Estrangeiros, se revestiam da altivez muito da maneira de ser do fundador da Nação. Ele não queria que se cerceasse a sua liberdade imperial, até para nomear arcebispos, dentro das tradições regalistas de seus antepassados de Portugal. Os dízimos seriam cobrados pelo Estado, mesmo porque o clero já vivia com subvenção oficial. Queria para ele o Grão mestrado das ordens militares, sobretudo a da Ordem de Cristo. Se os bispos eleitos pelo Brasil não recebessem confirmação, ou a confirmação demorasse muito, ele os faria sagra pelo Metropolita da Bahia. E queria logo um núncio na sua corte, nisso concordando o Papa, mas com subvenção igualmente, com o que não concordaria depois do Congresso”.
\end{abstract}

Cabia ao Imperador não somente nomear os bispos e os arcebispos, para que a Santa Sé a confirmasse, como também recorriam os que renunciavam aos seus bispados, chegando ao passo de Dom Tomás suplicar a misericórdia de Dom Pedro I para que aceitasse a renúncia do bispado.

Outro aspecto importante foi que no início da organização administrativa do Estado, iniciou-se apoiada na burocracia eclesiástica, uma vez que, os ocupantes dos cargos eclesiástico tinham uma formação cultural muito grande, destacando-se dos demais.

A Constituição de 1824 através dos artigos 5 e 102 implantou o Padroado Civil, mantendo o regalismo no Brasil e submetendo a comunidade eclesiástica ao exercício de uma série de funções civis, que praticamente faziam eles o papel de funcionários públicos, dando a eles um papel influente na comunidade local, inclusive para dirimir os conflitos entre os membros da comunidade. 
Os registros de vida das pessoas aconteciam dentro da Igreja católica, não existiam os cartórios de registro civis, então ao nascer o registro de batismo era o que servia como prova de nascimento, o casamento se fazia prova no documento expedido pelo pároco local e quando da ocasião da morte, os enterros eram também feitos nos cemitérios atrás das igrejas locais, sendo de controle paroquial. Não existia nenhum registro a não ser os que a Igreja local fazia.

Na visão de Azevedo (1978, pág. 122-123) apud Santirocchi o papel da Igreja se consolidava, dando a ela prorrogativas no papel administrativo do Estado:

\begin{abstract}
"Os clérigos possuíam uma religiosidade epidérmica e formal, apegada a certas regalias e acostumada a vantagens incômodas, porém aliciantes, que o Estado oferecia. Entre elas pode-se citar a estabilidade nos cargos, as côngruas (mesmo baixas e sempre atrasadas), a subvenção ao culto, jurisdição sobre vários atos mistos como registro de nascimentos, matrimônios e óbitos, administração dos cemitérios, interpretação dos testamentos, inscrição dos eleitores e participação ativa nas mesas eleitorais (estes dois últimos até 1842/46), e a partir de 1850 o registro de terras”.
\end{abstract}

Através desse papel exercido pela Igreja, houve uma mistura do espiritual com material. Os representantes da Igreja agiam como representantes do Estado. Na visão de Santos (1971 e 2003) apud Santirocchi (2013) durante o Primeiro Império ocorreram várias disputas em relação a imposição do Padroado civil.

“As questões de teor eclesiástico foram uma constante nas disputas parlamentares do Primeiro Império e principalmente do Período Regencial, devido tanto à imposição do Padroado Civil à Igreja, quanto a uma contínua tentativa de integrar o clero à burocracia do Estado como um setor da administração pública, atingindo até mesmo os templos católicos, com um decreto de 26/03/1824, designados para local de realização dos pleitos eleitorais, que deveriam ocorrer após a celebração de uma missa com homilia apropriada para ocasião”.

Na visão de Oliveira (1964: 75) apud Santirocchi (2013) os assuntos eclesiásticos eram tratados como assuntos de interesse da administração pública, como descrito a seguir.

“Os negócios eclesiásticos eram despachados como quaisquer outros assuntos da administração pública. Os padres e os bispos eram tratados como funcionários públicos de uma maneira muito mais incisiva do que havia feito a coroa portuguesa” (OLIVEIRA, 1964, pág 75).

Santirocchi (2013) discorre sobre a necessidade do clericado à época, manter uma lealdade tanto a igreja quanto ao Estado, fortalecendo a influência política da Igreja, mas enfraquecendo a Igreja como religião.

“O Padroado Civil criado pela Constituição, juntamente com o regalismo, impôs ao clero uma dupla lealdade: ao Estado e à Igreja. Este sistema de dupla 
lealdade

começou

a

ser questionado a partir dos anos de 1840/50 com o início de uma sistemática reforma da Igreja no Brasil, levada a cabo pelos bispos ultramontanos”. (SANTIROCCHI, 2010)

\subsection{Os conflitos da Regência Feijó com o Vaticano}

A crise com o vaticano ganhou maiores proporções no período da regência do Padre Diogo Feijó, que fora eleito Regente uno, ainda no período onde Dom Pedro de Bragança ainda apresentava tenra idade para assumir o cargo de imperador.

Em seu discurso de posse para a Câmara e o Senado, no dia 27 de outubro de 1835, manifestou-se com as seguintes palavras em relação aos brasileiros e a religião:

\footnotetext{
“A Religião, base da prosperidade pública e individual, verdadeiro apoio das leis, sólida garantia da moral, será mantida e profundamente respeitada. O Tribunal, porém, da Consciência será imperscrutável ao Governo, e o homem religioso poderá, debaixo da proteção constitucional, fazer livre uso dos princípios que a razão lhe ditar.”
}

Com a resposta negativa do Vaticano em aceitar a nomeação do bispo eleito para a diocese, o Regente Feijó manifestou-se que o governo tem ao seu lado a lei e a justiça, desonerando-o com a negativa do Papa, o governo brasileiro de agir com condescendência com a Santa Sé, porém não deixando de respeitar e obedecer ao chefe da Igreja Universal, tendo dito em seu discurso:

"Não posso, contudo, ocultar que sua Santidade, depois de dois anos de explicações recíprocas, resolveu não aceitar a apresentação imperial do bispo eleito desta diocese.” (Brasil Gerson, 1978: 107)

Em reação a negativa da nomeação do bispo eleito no Brasil, Regente Feijó restringiu a autoridade pontifícia no império, face a pressão exercida pela Comissão Eclesiástica da Câmara:

"O Decreto, datado de 18 de julho, negou licença para que os cidadãos brasileiros recorressem à Santa Sé para pedidos de dispensa de impedimentos em primeiro grau da afinidade lícita em linha lateral (nos casamentos) e para outros pedidos também (aos cidadãos comuns e aos prelados igualmente), vigorando essa proibição enquanto o papa não dispusesse a reconhecer os legítimos direitos do Brasil no caso de bispo eleito. E para que assim não se tornasse nulo ou ilusório esse direito de nomeação, que competia ao governo pelo bem do Estado, e pelos próprios cânones da Igreja.” (Brasil Gérson, 1978: 110) 
Até a edição deste decreto, esses recursos vinham sendo feitos diretamente ao Papa, sem que houvesse a interferência do governo, mesmo tendo o Código Criminal de 1830 criminalizado requerimento de brasileiros a autoridades estrangeiras sem a licença do imperador, demonstrando o tipo de controle existente sobre os brasileiros:

\footnotetext{
“Art. 81. Recorrer á Autoridade Estrangeira, residente dentro, ou fóra do Imperio, sem legitima licença, para impetração de graças espirituaes, distincções ou previlegios na Jerarchia Ecclesiastica, ou para autorização de qualquer acto religioso.

Penas - de prisão por tres a nove mezes.”
}

O desgaste causado pela Regência de Padre Feijó gerou uma instabilidade interna que deu ensejo a Revolução Liberal de 1842. Na visão de Marinho (1844) e Andrade (1942) apud Santirocchi (2013):

\begin{abstract}
“A Revolução Liberal de 1842, ocorrida nas províncias de São Paulo e Minas Gerais, foi um dos movimentos sediciosos que agitaram o Brasil durante o Império, trazendo consequências diretas para a Igreja. Como na maioria das revoluções ocorridas em território nacional até aquele momento, a participação de padres foi grande em ambos os lados. Entre os revoltosos encontravam-se o P.e Feijó, o cônego José Antônio Marinho, além de outros clérigos como: José Bento Ferreira de Melo, Joaquim Camilo de Brito, José Bento, Marciano de Cerqueira, Francisco de Paula Moreira, Manoel José Dias, Antônio e Urbano dos Reis Silva Rezende, Manuel Dias do Couto Magalhães e Ferreira da Fonseca. Durante o desenrolar do conflito, os futuros bispos das referidas províncias, os padres Antônio Viçoso e Antônio de Mello, assumiram a defesa da ordem e da autoridade constituída, fato este que não passou despercebido ao jovem Imperador e seus conselheiros”. (MARINHO, 1844; ANDRADE, 1942)
\end{abstract}

Funcionando também as custas do Erário Público as Relações Eclesiásticas e os juizados inferiores, que julgavam as causas privadas e as questões relacionadas a economia interna da Igreja. Também cabia ao imperador estabelecer a tabela de serviços a serem pagos a igreja, pelos serviços religiosos prestados, esta tabela poderia ser estipulada por decreto imperial.

Através de uma lei datada de 12 de março de 1842, institui como feriado todas as datas festivas da igreja, bem como todos os dias santo de guarda.

Durante o período imperial o próprio governo considerava misturada a parte espiritual com a temporal, ou seja, não se poderia identificar com precisão aonde começava a igreja e aonde começava o Estado, assim permanecendo até a Constituição de 1891 onde o Brasil tornou-se um Estado laico, separando definitivamente a Igreja e o Estado. 
6. Considerações finais

A Igreja católica no Brasil, marcou a colonização, influenciando a cultura através de seus festejos, dos sacramentos e da participação que os clérigos tinham junto a comunidade que faziam parte.

Após a Constituição de 1824 o Estado, através do Regalismo, se fortaleceu em relação a Igreja católica, influenciando nas escolhas dos bispos, na nomeação dos padres, exercendo estes o papel de representantes administrativos, atuando como representantes do Estado.

Uma demonstração disse é que não havia registro civil, sendo todos os atos da vida da pessoa registrados na igreja de onde moravam. Além de respeitar os aspetos da lei canônica, a Igreja era também responsável por preservar o cumprimento das leis do país.

A Constituição de 1824, através do artigo $5^{\circ}$, assegurou a religião católica como sendo a oficial do Brasil, mas permitia o culto domiciliar de outras religiões, sendo que as outras religiões não poderiam ser abertas ao público. Essa limitação da constituição, restringiu a liberdade religiosa, fazendo com que o Estado assuma um papel de zelador da manutenção da igreja católica dentro do território brasileiro. A mesma constituição trouxe em seu artigo 102, que caberia o Imperador a atribuição de nomear padres e bispos, uma demonstração real do intervencionismo do Estado na organização administrativa da Igreja.

Além da Constituição de 1824, trouxemos a I Constituição do Arcebispado da Bahia que trouxe a normatização dos atos da Igreja dentro do território brasileiro; bem como, a criminalização através do Código Criminal de 1830 da prática de outras religiões que não a oficial fora do ambiente doméstico, assim como, criminalizou o requerimento de brasileiros para autoridades estrangeiras, sem a devida autorização imperial.

Ao longo do período imperial o Estado saiu bastante fortalecido em relação a Igreja, gerando sobre uma subordinação. A distância física entre o Brasil e a Santa Sé, tornavam os processos de nomeações e consultas, muito lentos, deixando de atender aos interesses diretos da coroa. O Imperador, constitucionalmente investido como chefe da Igreja passou a assumir todas as nomeações e todos os atos papais só teriam valor no Brasil se devidamente autorizados por ele.

A Santa Sé, não satisfeita com as medidas do governo Brasileiro, recusou a nomeação do bispo eleito para o Brasil, gerando assim um descontentamento e um posicionamento forte 
do governo brasileiro, que passou a impedir que os brasileiros fizessem qualquer tipo de requerimento ao Papa, sem que fosse autorizado por ele.

As interferências do Estado na Igreja fragilizaram a relação com a Santa Sé e deram a Igreja local (paroquial) uma força política muito grande, nenhum ato civil era praticado sem passar pela Igreja, assim também como os párocos passaram a atuar como mediadores de conflitos.

Até o final do Império, vários conflitos internos e revoltas ocorreram devido a dificuldade que os regentes tinham de exercer o controle da soberania interna. A Igreja permaneceu junto ao Estado enquanto o Império esteve fortalecido, com a proclamação da República, o Estado laico se fortaleceu e a Igreja católica passou novamente a jurisdição integral da Santa Sé, não tendo mais o governo responsabilidade na formação e na manutenção da Igreja.

A liberdade religiosa existente no Brasil fez com que outras religiões encontrassem espaço e pudessem crescer dentro do território brasileiro, gerando uma sociedade multireligiosa e multicultural.

\section{Referências Bibliográficas:}

ANDRADE, Martins de. A Revolução de 1842. Rio de Janeiro: 1942 apud SANTIROCCHI, Ítalo Domingos. A Igreja a e construção do Estado no Brasil imperial. Natal. 2013.

AZEVEDO, Thales de. Igreja e Estado em tensão e crise: a conquista espiritual e o padroado na Bahia. São Paulo: Ática, 1978 apud SANTIROCCHI, Ítalo Domingos. A Igreja a e construção do Estado no Brasil imperial. Natal. 2013.

BORGES, Leticia e Arruda, Camila. A questão religiosa na formação do Estado brasileiro: um estudo sobre a formação pátria da Colônia a República. Estudos em homenagem a Arno Wehling, org. Nunes, Claudia at all.Editar Editora Ltda S.A. Juiz de Fora. 2017.

BRASIL, Gerson. O Regalismo Brasileiro. Editora Catédra. Rio de Janeiro. 1978.

I CONSTITUIÇÃO DO ARCEBISPADO DA BAHIA. 1707. Biblioteca do Senado Federal. 
CONSTITUIÇÕES BRASILEIRAS. Constituições 1824. Volume I. $3^{\text {a }}$ edição. Brasília. 2012. Biblioteca do Senado Federal.

CÓDIGO CRIMINAL. Lei Imperial de 16 de dezembro de 1830. Disponível em: www.planalto.gov.br. Acesso em: 11 de dezembro de 2017.

MARINHO, José Antônio. História do movimento político que no ano de 1842 teve lugar na Província de Minas Gerais. Rio de Janeiro: Tip. J.E.S. Cabral, 1844 apud SANTIROCCHI, Ítalo Domingos. A Igreja a e construção do Estado no Brasil imperial. Natal. 2013.

OLIVEIRA, Oscar de. Os dízimos eclesiásticos do Brasil nos períodos da colônia e do Império. Belo Horizonte: UFMG, 1964 apud SANTIROCCHI, Ítalo Domingos. A Igreja a e construção do Estado no Brasil imperial. Natal. 2013.

SANTIROCCHI, Ítalo Domingos. A Igreja a e construção do Estado no Brasil imperial. Natal. 2013.

SANTIROCCHI, Ítalo Domingos. Os ultramontanos no Brasil e o regalismo do Segundo Império (1840-1889). (Tese de doutorado). Roma: UNIGRE, 2010 apud SANTIROCCHI, Ítalo Domingos. A Igreja a e construção do Estado no Brasil imperial. Natal. 2013.

SANTOS, José Augusto dos. Liberalismo eclesiástico e regalista no Brasil sob o pontificado de Gregório XVI. (Tese de doutorado). Roma: UNIGRE, 1971.

- "Relações Igreja-Estado no Brasil Imperial: Início do Contencioso do Período Regencial”. In: Revista do Mestrado em História. Vassouras: v. 5, p.89-110, 2003 apud SANTIROCCHI, Ítalo Domingos. A Igreja a e construção do Estado no Brasil imperial. Natal. 2013.

SCAMPINI, José. A Liberdade religiosa nas constituições brasileiras. Editora Vozes. Petrópolis. 1978. 